University of Nebraska - Lincoln

DigitalCommons@University of Nebraska - Lincoln

Faculty Publications: Department of Teaching, Department of Teaching, Learning and Teacher Learning and Teacher Education

September 2007

\title{
Seeking refuge in literacy from a scorpion bite
}

Loukia K. Sarroub

University of Nebraska-Lincoln, Isarroub@unl.edu

Follow this and additional works at: https://digitalcommons.unl.edu/teachlearnfacpub

Part of the Teacher Education and Professional Development Commons

Sarroub, Loukia K., "Seeking refuge in literacy from a scorpion bite" (2007). Faculty Publications: Department of Teaching, Learning and Teacher Education. 34.

https://digitalcommons.unl.edu/teachlearnfacpub/34

This Article is brought to you for free and open access by the Department of Teaching, Learning and Teacher Education at DigitalCommons@University of Nebraska - Lincoln. It has been accepted for inclusion in Faculty Publications: Department of Teaching, Learning and Teacher Education by an authorized administrator of DigitalCommons@University of Nebraska - Lincoln. 


\title{
Seeking refuge in literacy from a scorpion bite
}

\author{
Loukia K. Sarroub \\ University of Nebraska-Lincoln
}

44E Henzlik Hall, Lincoln, NE 68588-0355, USA. Email: 1sarroub@unl.edu

The purpose of this study is to examine a refugee boy's experiences with literacy in and out of school in the US. Within these contexts, I explore this youth's literacy development in light of his identity as a poor Yezidi Kurdish refugee from Iraq. Central to the article are two main themes. The first, life as a scorpion sting, explicates the young man's life as a refugee, and the difficulties he faces in and out of school. The second theme, reading for mayonnaise, alerts us to the limitations of literacy programs in which unconnected texts and distanced narratives are prominent, and individuals' real lives are, for the most part, ignored and marginalized even with the presence of exceptional teachers.

\section{Introduction}

Nearly 2 million Iraqis fled the fighting during the first Gulf War. Though most returned at the end of the war, a greater number remained in countries of first asylum, such as Syria, Jordan, Turkey, and Saudi Arabia, fearing persecution in Iraq. Some 39,000 , including ethnic and religious minorities and others who participated in the uprising against the Iraqi regime, remained in refugee camps in Saudi Arabia, and in $2001,40 \%$ of the total refugee population and people of concern (19.8 million) to the Office of the United Nations High Commissioner for Refugees (UNHCR) were living in camps. It is estimated that by 1994, the US had accepted 591,000 refugees and asylum seekers. In 2001, North America became the new home of 650,000 refugees (http://www.unhcr.ch/cgi-bin/texis/vtx/basics).

In 2006, an additional 1.5 million Iraqis were displaced from Iraq and traveled to neighboring countries, such as Syria, to begin new lives. As reported by CNN, since 2003 , only 464 Iraqi refugees were allowed into the US; but in 2007, 7000 will be allowed to seek refuge in the US following international criticism that the US has not participated in facilitating resettlement (CNN News, February 14, 2007). Presently, it is estimated that $30 \%$ of the displaced youth do not attend schools in their new settings. The children of families who resettled in the US prior to the war in 2003 after long stays in countries such as Syria or Turkey, arrived with a variety of school experiences. Many lacked preparation for formal school at secondary level. In this article, 
I explore how a young man who had very little formal education in Syria and Turkey negotiated educational opportunities in the US, ultimately failing out of school. Beginning in the fall of 2002, as I learned about Hayder over the next year and a half in and out of school, it became clear that the classroom in which he was observed presented just one reality in his life.

The United States Department of Education data show a current count of 3.8 million students in public schools with limited English skills. The US has agreed to accept refugees, such as Hayder, and their families, and schools must be better prepared to teach them until they and/or their parents, together with other institutions, find ways to make a life for themselves. Hayder, a Kurdish seventeen- year-old refugee from Iraq, mentioned that the scorpion bite in his neck prevented him from learning to read. Listening to his scorpion bite story in Ms. Kleibel's high school English Language Learner Literacy class, I marveled at Hayder, who was clearly one of the better readers in the room. I wondered why this young man was so certain that he could not learn, that he was not well on his way to becoming literate in English. He had just successfully read a passage about scorpions and made a connection to a traumatic event in his past. He had just read the word 'scorpion' on his own.

Hayder's story of the scorpion bite would metaphorically explain the limitations to success he experienced as a young man coming of age in the US. Several factors contributed to Hayder's identity as a learner in a new society: his masculinity as a Kurd, his low socio-economic status, his experiences with war and survival, his propensity for fighting, his responsibilities at home, his determination to find a job to support his five brothers and parents, and his car troubles. The ethnographic analysis of the case of Hayder is useful in unmasking geopolitical notions of literacy and identity across home, school, and work contexts. This frame of reference is especially helpful in delineating the contextual uses of texts and language among ethnically, linguistically, and religiously diverse populations. It became important to understand the relationships among this young man's social status as a refugee, the reading instruction with which he engaged, and his attempts to stay in school. While I cannot address all the ways in which schools, families, and communities might help one another in this endeavor, I posit a definition of literacy that crosses barriers, such as schools, families and work places. Literacy is fluid, it changes from context to context, task to task. As Hayder discovers, reading means knowing that a 'scorpion' bit you and learning to say and write 'mayonnaise.'

Teaching reading at secondary level can be difficult, cumbersome, and challenging. Often, secondary students are reluctant to read, bored with the monotony of their school lives, and distracted by their out-of-school responsibilities, obligations and/ or social pass-times. On the one hand, in the case of Hayder, having to drive his brothers to school, earn money, repair his car, take care of his parents' needs, pay bills, get along with people who provoked him to fight-all of these responsibilities made him into a less than desirable student. Many teachers enter the reading classroom with ambitious agendas, only to finish the first school week doubting their abilities to teach reading and engage high school aged students into the practices of good readers. Often, students are assigned a task or project, the student completes the as- 
signment, and there is little reflection or articulation of the student's learning process or the steps involved in completing the task. As students have little exposure to across-content understanding of their work, literacy instruction can be important and meaningful if students see value in reading, and if teachers make explicit connections to those realities and validate students' ideas. As Hawkins (2004) notes, 'we must rid ourselves of the assumption that good teaching results in language learning and academic success' (p. 21). Hawkins points out that negotiating new vocabulary and grammatical structures goes hand in hand with sociocultural competence. In secondary classrooms that focus on reading instruction, this is difficult because there are not readily available curricular materials that address the social and academic needs of youth. Yet, teachers do make intellectual and compassionate connections, and these are key dimensions that characterize teaching on a good day. Teachers can support students with the multiple literacies they already practice, make across-text and across-content connections, and see literacy as a communicative tool and entry into a special community that relates to their in and out of school life.

If the goal of literacy teaching is to engage students in lifelong literacy, it is important to understand the tools available to promote literacy. Researchers suggest that students need exposure to multiple texts. Meaning making events or literacy events can encourage students to acquire a deeper understanding of classroom material, as they are able to connect texts from outside experiences to the information presented in class (Hull \& Schultz, 2002). It would have been useful for Hayder's teachers and parents to know more about his use of print in video games or the words list he kept in the car as he drove in town. Moje et al. (2000) argue that all material that contains significant meaning can be considered a text. One makes meaning from a text by connecting one's lived experiences. Context plays a role in students' meaning making because the atmosphere and immediate surroundings often affect a student's interest or disinterest and interpretation.

Giving students the opportunity to explore multiple texts can be one way to show students the value of their current practices while supporting new modes of meaning making. With a more inclusive definition of texts, literacy teachers can support multiple literacies in the classroom. While moving beyond the concept of print literacy may seem challenging, there are benefits to including multiple literacy perspectives in the classroom, and students become more socially and academically developed. For example, in contrast to Albright (2004) who describes literacy as anything that gives us the opportunity to represent ourselves and has meaning, Morrell (2002) describes two different kinds of literacies: academic versus critical literacy. He points out that academic literacy is the literacy that is taught in classrooms through traditional texts, reading, writing, and discussing, while critical literacy is the ability to read and write, and also think critically about how the world, society, and our communities have influenced the text. If multiple texts are valued in the classroom, and students are supported in their discussions, reflections, and responses to various texts, then teachers can help students acquire both academic and critical literacy. Teachers can support students as they compare and contrast various genres, topics, concepts, theories and ideas, and they can connect the real world problems that refugees, such 
as Hayder, have in the work place to learning how to read and write for meaning and for resilience. As Morrell (2002) notes, 'the critically literate can understand the socially constructed meaning embedded in texts as well as the political and economic contexts in which texts are embedded' (p. 73).

\section{Fieldwork and analysis}

Lincoln, Nebraska, has an approximate population of 220,000 people, and is located in the middle of the US. It is surrounded by meat-packing factories, Goodyear plants, and farm industry. Some towns within a three-hour drive of the city have populations that are $85 \%$ Spanish speaking, and very few resources for teaching literacy to the growing numbers of students from families that are not print literate in English. There are five high schools in Lincoln, and Main High School served approximately 1950 students in grades 9-12 in 2003. According to a school information pamphlet, the high school has about 150 students in ELL classes. In 2003, the students spoke at least 20 different languages. The largest group spoke Spanish and the next four largest groups spoke Arabic, Vietnamese, Bosnian, and Kurdish. The total student body was made up of 77\% European American students, 10\% African American, 5\% Asian American, 6\% Hispanic, and 2\% Native American. Nearly 40\% of all students were on free or reduced lunch.

Hayder's story is an important one because his life is part of a complex web of experiences that connects survival, war, and schooling. It sheds light on what it means to end up in the middle of everywhere, as Pipher (2002) suggests. The Midwest and panhandle regions of the US are changing demographically, and schools are facing the challenge of change as well. Hayder's case presents a multitude of areas for query, each affecting his literacy success, yet I asked three overarching questions that seem particularly relevant to his situation, and the situation of students like him: What does literacy look like at the secondary level? What does literacy look like in Hayder's life? Why is Hayder failing out of school and work? My approach to this study built on prior experiences in conducting fieldwork in Middle Eastern communities and elsewhere (Sarroub, 2001, 2002a,b, 2004, 2005).

Hayder represented, as one of his teachers put it, 'a smart young man with lots of problems.' Hayder is representative of many of the young male refugees from the Middle East. He was selected to be a focal student with the help of Ms. Kleibel because of his steady progress in reading (despite his dismal attendance record), and as she put it, his 'strange' experience with a scorpion bite, his low socioeconomic status, and his failure to stay and succeed in school. I had conducted 18 months of fieldwork in the community and the public high school he attended. I systematically carried out observations in two of his ELL literacy and language acquisition classes during the fall of 2002 and the spring and fall of 2003. Given the apparent cultural constraints regarding men and women in Hayder's home life, a male research assistant visited Hayder's home and shadowed Hayder twice for an entire day, from morning to evening. Hayder was interviewed formally and informally, as were his teachers. Field 
notes were written after every encounter or observation of Hayder. Constant comparative analysis was used to examine the data, and this included weekly or biweekly analytical memos and the coding of field notes.

Classroom observations were made twice a week. Informal telephone conversations maintained regular contact with Hayder outside of school. Semi-structured interviews were conducted using the protocol of Spradley (1996) for ethnographic interviews, and a domain analysis of the first interview generated questions for the follow-up interviews. Data collected includes semi-structured interviews and open, exploratory questions with Hayder and his teachers. Participant observation was conducted in the contexts of school, community, home, and work. Hayder was 'shadowed' at school, and his various literacy practices were coded along with those of his peers in his reading classes. Classroom sessions were videotaped over the course of one semester to capture oral interactions and responses to various print texts. Reading assessments were conducted with Hayder to determine approximate reading levels. When I first met him, he could decode and comprehend printed text at a second grade level, and he had no trouble communicating in English. Artifacts, such as school work samples, personal work samples, community demographic information, daily written bulletins, memoranda between district superintendent and principals, memoranda from principals to faculty, memoranda from the community liaison, and media information, were collected.

A case study design (see Erickson \& Shultz, 1992) was used to document Hayder's literacy and discourse practices, and attention to the particulars of the case illuminate his own construction of his identity across school, home, and work settings. The complexities of student life outside school often have a huge impact on the successes or failures that students have while in school. In order for students to be successful in school, they must be literate enough to understand the academic concepts and skills that they are being taught. The importance of connecting home and school literacies becomes even more significant for refugee and immigrant students. They not only experience the same challenges and problems as their American peers, but they also have the added burden of limited proficiency in English while trying to make sense of a different culture.

Two main themes emerged from the fieldwork analysis (Emerson, Fretz \& Shaw, 1995). The first explicates Hayder and his life as a refugee, and the difficulties he faces in and out of school in relation to a scorpion sting. The second theme alerts us to the limitations of literacy programs in which unconnected texts and distanced narratives are prominent, and individuals' real lives are, for the most part, ignored and made marginal, with the exception of teachers who attempt to make such connections.

\section{Hayder: life as a scorpion sting}

Hi. My name is [Hayder]. I am living with my parent in Lincoln. I am kind of confused around. Why? Because I got so many ticket, that is why. I have to pay my ticket 
and fix that car to drive to school. That is what I need to do to find a job where I can work more than two hours a day. My dream is school and seeing all of my teachers smiling and happy. Like Mrs. Kleibel and Ms. Sue. This note is made by [Hayder]. I want to learn how to write and read, that is all of my dream. I want to be happy for the rest of my life. I am gave up tickets. I am not going to drive fast anymore. You know what? I have to stay home for a while, four to five months, without making trouble. I am going to stay home and read and write. I want to be happy the rest of my life.

I first met Hayder in the ELL literacy class. Ms. Kleibel, then in her third year of teaching this class, was part of a district wide professional development grant whose aims were to help fourth through twelfth grade students with limited formal schooling. The growing numbers of refugee students arriving from Vietnam, Iraq, the Sudan, Afghanistan and elsewhere with little or no formal education and limited or no experiences with print, mobilized teachers to engage with one another about the teaching of reading. Ms. Kleibel, for example, met regularly with elementary, middle, and high school reading, math, and technology teachers as well as K-12 media specialists as part of a funded grant throughout the academic year, and reviewed reading strategies that she would then implement in her classroom. During the summers, the teachers offered a summer school option to students with limited formal schooling, and coached them one-on-one or in small groups. Mrs. Kleibel adapted the Cunningham and Allington (1999) 'making words' and 'word wall' activities; she created centers in her classroom; and with our help and the help of paraprofessionals and high school student helpers, she encouraged students to partake in guided reading activities. For example, my research assistants and I guided students individually or in pairs through sets of picture books selected for guided reading with the support of grant funds or that Ms. Kleibel had checked out from the public library, and it was during such a time that I met Hayder.

Hayder did not say much in class, and when he said hello while walking into the room, his mouth would creep up into a lop-sided smirk. He was pleasant, up-beat, intelligent, and personable, yet, at times, he became frustrated and discouraged by the slow process of learning English. Hayder told us that he was lonely because of his isolation from friends and American students; he worried about his jobless situation, and only his class assignments could distract him from voicing those worries. In class, Hayder told stories about his uncles or father in Iraq. He would talk about events and friends at work. Over time, we began to understand that these stories were integral to his identity-a male, refugee, ELL student, who seemed to be trying to understand how the world worked in the US.

Hayder is a Kurdish, Yezidi refugee, and when I first met him, he had lived in the US for three years. He lived with his mother, father, and five younger brothers (another brother still lives in Kurdistan) in the poorest section of the city, where rent is government subsidized. Surrounded by other refugees, immigrants, and poor white and black families in this neighborhood of dilapidated houses and unkempt lawns, Hayder's family seemed to be forgotten, living out a life of the American underclass that did not encourage the dignity of his past life in a substance farming community in Iraq. The family followed their cultural norms of sleeping on mattresses placed di- 
rectly on the floor, but they lacked bedding, such as blankets and pillows. The rental house was void of furnishings besides two couches, a kitchen table, and a dresser. The family's most prized possession seemed to be the television, which was turned on most of the time. Hayder's father and brothers watched TV throughout the day as they went in and out of the house, and Hayder's mother worked in the kitchen.

Hayder's parents were not employed. His father lost his job because of a fall at work that now required him to use a crutch as he walked. There was always a group of men, old and young, in Hayder's home, and they would sit and smoke and watch TV and talk about politics. None had jobs. Hayder told us that he and his father had worked hard as farmers in Iraq and the refugee camps, but now they could not find work in Lincoln. They were poor. Hayder's parents could not speak English and they were unable to read and write in any language. In relation to his own sense of self as a refugee and a student, Hayder expressed confusion. The 'confusion' compounded by his very calm demeanor and frequent unstressed intonation and drawn out words when speaking, prompted Hayder's teachers to say that Hayder seemed 'foggy,' 'groggy,' or 'out of it.'

When Hayder had trouble recalling his past experiences or if he thought he was not learning to read quickly enough, he would talk to his teachers and to us about being confused, and he would attribute that confusion to a scorpion bite he said he received when he was in a refugee camp. Hayder had a scar on his neck that, he said, was from the scorpion. Initially, the scorpion bite was a frequent story that Hayder told, reporting that the effects from the bite were memory and language loss and the inability to concentrate. Hayder even spoke about going to the doctor to get 'medicine' for his bite. The scorpion bite was a central narrative in his school life and in his relationship with me and with his teachers. None of us who listened knew how to help him, specifically in response to the long-term affects of the scorpion bite.

While Hayder's religion seemed central to his identity — not coming to school for Kurdish celebrations and holidays - his knowledge of his family's religious practices was limited and frequently he was unable to articulate his beliefs. We were surprised by his inability to explain his religion to us, and we suspect this had less to do with his ability to speak in English than it did with a certain reticence around this topic, for he could talk at length and in detail about 'girls' or 'fights.' This led me to do some research on the Yezidi.

The Yezidi number approximately 60,000 in Iraq and Syria, and 200,000 worldwide. Their beliefs are a complicated mixture of Islamic, Gnostic, Jewish, and Shamanistic elements. There is no specific Yezidi holy text. Yezidi tradition is strictly oral, and consists of Kurdish prayers, songs, and hymns. Yezidi is related to Yezad, the Arabic word for angel, and worship centers on angels, the most important of which is Melek Taus, the 'Peacock Angel' or 'Lucifer,' Archangel and creator of the material world. The Yezidi believe that Lucifer was forgiven for his transgression, and it is forbidden to refer to him as the devil or Satan. The Zoroastrian priests forbade anyone who did not belong to the priestly or princely class to gain literacy, and traditionally Yezidism barred literacy altogether. In fact, it has been asserted that until the beginning of the twentieth century only one man among the Yezidis, the cus- 
todian of the Jilwa, knew how to read (Guest, 1987, p. 33). This ban is not regularly enforced although large numbers of Yezidis are still not keen on literacy.

After his family and people's persecution by Saddam Hussein's policies to bring Kurds in line with his regime, Hayder's only formal education took place in refugee resettlement camps in Turkey and Syria prior to arrival in the US. Hayder has an ear for languages, but within the socioeconomic class system he inhabited, literacy was not important until he was sent to school in the refugee camps and then in the US. I was curious about Hayder's participation in religious and cultural practices, and how he negotiated these with his teachers given that he was not able to articulate Yezidi traditions and holiday practices. Here is an excerpt from fieldnotes that illustrates the tensions he experienced in and out of school.

Hayder turns to Mrs. Bloomberg, his math teacher, and said, "I will not be at school tomorrow." Mrs. Bloomberg says, "Why, did you get in trouble with attendance again?" Hayder says that it's a holiday. Mrs. Bloomberg says, "You have a holiday tomorrow?" She tells him he's been missing too much school then asks what holiday it is. Hayder says that he "doesn't know." Mrs. Bloomberg questions, "If you don't know what holiday it is, then why would you not go to school?" Mrs. Bloomberg then tells him that he will get in trouble with attendance again if he keeps missing school will get no credit for his classes, just like last year. She tells Hayder that even though there is a holiday, he should come to school. Mrs. Bloomberg asks Hayder what he does for this holiday and Hayder tells her that he "has food and people put things on the table." Again Mrs. Bloomberg asks Hayder what the name of the holiday is and he said that he does not know.

Hayder's experience in not being able talk about holidays or cultural matters with his teachers was not unique to him. Other Iraqi and Kurdish students whose traditions, cultures, and religions did not fit within the 'mainstream' knowledge that is commonly available about Christianity, Judaism, and Islam experienced a dissonance, in part because they could not find the appropriate ways to describe it in English, and in part, because the teachers themselves did not have a set of references about the Yezidi or Wahabi religious practices, for instance, that they could draw on to understand their students. In other words, neither the students nor the teachers could find some common repertoire or frame of reference for talking about the 'unusual' events that occurred at home which influenced participation at school. In Hayder's case and from the school's perspective, the holidays for which he stayed at home became truancies.

At times, teachers were concerned that Hayder was involved in drugs because of his tardiness to class. In one e-mail message, Ms. Sajac wrote: ' ... A prognosis for Hayder is tougher. He's been late about 5 times, and each time puts him a little deeper in a fog... So that isn't so good.' The same teacher, in a second e-mail message, commented, 'Maybe we've touched on this before. His fogginess, that is ... Being late and absent puts any kid a step behind.' Ms. Kleibel noted that Hayder blamed his forgetfulness and troubles in life to the scorpion bite, and that she did not know what to make of that since he seemed to do well in reading when he was in school. 
Concerned by his teachers' view of Hayder, I attempted to answer the 'drugs' question more definitively because our observations of Hayder showed no indication of use in or out of school. He attributed his forgetfulness to the scorpion bite. Hayder was a smart student who made many breakthroughs in school, but those accomplishments were usually overshadowed by his life outside of school. He dropped out of school twice, and when he was in school his attendance was sporadic, which led to in-school and out-of-school suspensions that ultimately kept him out of the classroom even more. The inconsistency in his dedication to school and his red, bleary eyes affected his grades and his academic progress. Due to his teachers' perceptions of him as a drug user, I turned to Hayder's out-of-school literacy life to explain the conditions that generated foggy behavior and blood-shot eyes.

\section{Reading for mayonnaise}

Yes, Hayder is in my Level 2 ELL class. I have known him for a long time. He was first in my class 2 years ago, in Level 1. At that time, he missed lots of days and wasn't really tuned in much at all. He did behave and do his work; he was just not there much and eventually he dropped out. The same thing happened last year. He was in my Level 1 Reading class. It was 2nd period, at 8:00, and he just couldn't get there. He always had excuses: trains, car problems, etc. He made up work as requested, but eventually started missing more and more until he dropped out.

This year he certainly has appeared to be more serious about school. He has been here and been on time until today. He was absent, so that concerns me. Hopefully, there is a good reason he missed class today. I went to CA for my son's wedding, so I have really only worked with him this year for less than two weeks. So far this year, he has been much more appropriate in classroom attitude and work habits than the last two years. He has taken one Hampton Brown test on which he scored 68. I give the students 10 extra points on their first-ever Hampton Brown test, because the format is often different than they have had before. So his score was 78-C. (Ms. Telhee)

In this section of the article, I address how Hayder negotiated literacy in and out of school and how he dealt with school and 'life' literacy. In school, Hayder's literacy acquisition was guided by an adapted-to-high school-level early reading curriculum. Out of school, he was functionally literate, using reading and writing for specific goals or outcomes. The two classes which Hayder attended included Ms. Kleibel's ELL Literacy class (which she called Basic Reading) and Mrs. Sajac's Level 2 Social Studies classes (which focused on cultures and narrative texts), each of which had six to ten students. As Ms. Kleibel remarked, 'The ELL Literacy class was by definition based on individual assessment and selection of materials for each student [who had had very little formal schooling experience or literacy instruction in any language]; the class size was very small so more communication with the teacher was possible. A Level 2 class [addressed] the needs of students without special needs as well as unique [cultural and linguistic] issues.' These teachers were part of a cohesive, collegial, and collaborative group of teachers who worked well with one another and with the guidance of a strong and innovative leader. They met often and worked together along two key dimensions: the reading component of academic life in high school 
and the social life component within the US. As we mentioned above, Ms. Kleibel was also part of a district-wide professional development group that was learning how to implement some early reading strategies in their classrooms.

Ms. Kleibel's instruction focused on spelling, vowel sounds and rhymes, syllables, making-words activities, and independent and guided reading. She liked to have her students read a variety of picture books or informational texts that she had checked out from the public library or that she bought with grant funds. Ms. Kleibel was a teacher who was very direct in her instruction and she had everything planned out each day. The students came into the classroom knowing what to expect - the beginning of class would be spent making words, where students would be given a set number of letters and then the teacher would say a word and the students would be expected to spell out the word with the letters they had. After the making-words activity, there would be a lesson on rhyming, vowels or some other phonics-like reading instruction. The remaining class period would be focused on individual reading, or group reading (sometimes choral reading), where the students put into practice the skills that they had learned in the making-words activity and the other phonics-like instruction.

Ms. Kleibel was a reflective teacher, who examined her instruction and made modifications based on her perceptions about what students needed. Throughout the year of observations in her class, she made modifications by breaking students into groups for more one-on-one attention, having the para-educator in the room work with one group, while she worked with another, and then switching half way through the class period. She would often return from her professional development group with lists of ideas that she attempted to implement in her classroom. She was aware of her students' ability levels, and would talk about the varying levels of progress that she saw her students making. She assigned homework related to the 'making-words' activities, and encouraged students to read at home by letting them borrow books from her classroom. As a result of her constant reflection and adaptation, and in addition to her structured instruction, she was strategic in her teaching style. Below is an example of how she guided one reading lesson from a reading passage. Ms. Kleibel guided Hayder's reading by making an analogy, and Hayder shows that he understands the concept of analogy by rhyming another example.

Hayder flourished in Kleibel's class. He was able to make connections in literacy, pulling together the reading, spelling, rhyming, and syllables. When he struggled, Ms. Kleibel pointed out rhyming patterns that helped Hayder identify and learn words. While Hayder did not always attend Kleibel's class on a regular basis towards the end of the year, he greatly improved in reading and was considered ready for Level 2 halfway through the academic year. However, his absences held him back. Ms. Kleibel commented that she often combined listening to Hayder talk about life outside of school with setting certain limits with him. At times she clearly redirected his conversation during instruction time. She did this when he began to repeat himself or 'get stuck' on a topic from his past, such as the scorpion bite. She followed this strategy because some of Hayder's conversation style characteristics (repetition 
of the same stories with increased emphasis on why he could not learn) would not be an asset in work settings, something important to him. As Ms. Kleibel noted, Hayder did not seem offended at this type of intervention or honesty alongside the reading instruction with which he engaged.

While Ms. Sajac's academic atmosphere was very different from that of Ms. Kleibel, the students liked her genial approach to teaching and to them. This was a class in which students were expected to work more independently, and while some met this challenge successfully, others, like Hayder and Karima (another ELL Literacy student), struggled in this class. Lessons were briefly presented at the beginning of class, and the majority of class time was spent on independent seatwork consisting of worksheets that were sometimes collected for a grade, or at other times the answers were given to the entire class. This type of independent work did not always hold students accountable for language learning, and the students would often copy one another and talk aloud as they shared answers. Whole group instruction was teachercentered. For example, when Hayder asked questions, he would often receive brief answers from Ms. Sajac, and sometimes his ideas would be ignored. This was due, in part, to his high tardy and absence record, which frustrated his teacher.

Ms. Sajac asks the class how they can write a topic sentence about babies with the words that she wrote on the board [beautiful, ugly, good, small, cute, blind, babies cry]. None of the students answer but Hayder has his hand raised, Ms. Sajac turns to the board and begins to write a sentence. Hayder says, "I have a question Ms. Sajac." Ms. Sajac does not say anything in return. She writes on the board, "Human babies are small living things who are cute and helpless." Ms. Sajac says that her topic has "big ideas" about the paragraph that she is going to write. She then asks the students for sentences that contain details about the topic sentence on the board. Ms. Sajac writes, "Babies sometimes cry because they need food or something else." Hayder said, "Ms. Sajac, human babies like music, the soft one." Sajac said, "Let's stick to these now," as she points to the board where she has words written down about babies.

In the example, Hayder raises his hand. He then interjects a comment to ask if he can ask a question. Hayder makes a third attempt, and Ms. Sajac does not take it up as another adjective she can add to her list of adjectives describing babies. We observed Hayder attempt to join class discussion on more than one occasion when he attended school, but he finally gave up. As in Ms. Kleibel's class, Hayder's attendance was sporadic, and our sense is that Ms. Sajac, who did her best, did think that Hayder still needed to make an effort to be there and to participate consistently. Hayder made little progress in reading and writing in the class.

As with Ms. Sajac's class, the social atmosphere of Ms. Kleibel's class was welcoming, and she made a social connection with Hayder. She knew him well and would often ask him about his family, his job situation, or his recent car problems. She took an interest in Hayder's life events, at times offering suggestions, advice, and support. Ms. Kleibel said that she coached him as to when to stop asking questions on any given topic in class because that would help him during job interviews. She was what Pipher (2002) calls a cultural broker, for example, helping Hayder 
with the school attendance appeals process or giving advice regarding car trouble and police officers.

Ms. Kleibel: "Oh Hayder, before you leave I have the answer to your appeal to the attendance committee. Come here." Ms. Kleibel walks to the back of the room and Hayder follows her. Ms. Kleibel says, "You can still pass your classes as long as your teachers are willing to let you make up the work. So, if you want to make up the work in my class you can still pass. Right now you have an F, but if you do the work we can change that." Hayder says that he wants to do the work. Ms. Kleibel said, "Now Hayder, don't get discouraged if there are other teachers that won't let you make up work. Don't just quit. Keep working hard and stay in school."

Hayder would frequently stay after class to speak with Ms. Kleibel about school and his job. It was easy to understand Ms. Sajac's frustrations. On several occasions, Hayder was absent or late. However, there were some missed opportunities to respond to and teach him, to encourage him to return and continue the work of learning to read and write in English. At the same time, no one teacher can be responsible for the choices Hayder made about his efforts to stay in school, and thus Hayder presents a dilemma.

Out of school, Hayder read for specific purposes. He read billboards, signs on buildings, instructions and messages at an ATM cash machine, and messages and directions while playing video games. He said that it was easy for him to learn words outside of school, especially when he was frequently exposed to them. He would make an extra effort to learn words that he felt were important to know. The example that follows is one in which Hayder went through the drive-through at a McDonald's restaurant:

Hayder says that when he goes to McDonalds he likes to have "that white stuff that you put on sandwiches." He says that it's like "sour cream, like Ranch dressing." I ask Hayder if he's referring to mayonnaise. Hayder says, "Yes, how do you say it again?" I repeat, "mayonnaise" for Hayder and he repeats "mayonnaise" five times. Then he says, "I need to write it down so I remember." Hayder looks around the car and pulls down the visor and gets a receipt and a pencil and writes "mayonaz" on the back of the receipt. He gets the food from the second window and asks the woman for some mayonnaise.

On a different day, Hayder parked the car facing west toward an intersection. Hayder stared in the distance and said that he did not like long words and said 'they are the hardest' for him to learn. 'Like pharmacy over there,' he pointed through the windshield and across the street at Walgreen's store. On the side of the Walgreen's building, in big red letters, it was printed, PHARMACY. Hayder read words everywhere he went, and he did so with an avid interest that belied his teachers' perceptions of him being in a fog. Along with writing every new word in phonetic approximation as he did with 'mayonaz,' Hayder would often read the words at the bottom of the television screen as they scrolled past in closed caption mode. Then, in school, he would talk about the films that he watched or ask questions about something that he had seen on television. 
Hayder also played a video game from the 1980s, Mario Brothers 3, reading the instructions on the screen as he proceeded one level to the next in the game. This is one game of the three in the series that allows players to select a box in which its contents will 'help you on your way.' There are war-like scenes that culminate the levels, and some levels have battleships and some have canons.

I sit in the basement and watched Hayder play the video game. He finishes a level of the game and a screen comes up that has a written message on it. The first time it said, "The king has been transformed, it is your job to find him and change the king back." Hayder sits there for a while, quietly, looking at the TV screen. He seems to be reading what was on the screen. Hayder shouts, "Oh it is terrible, the king has been captured." Then he goes to another level in the game and Hayder says, "Now going to go to war." He finished another level of the video game and another screen comes up with a written message. Hayder reads this message aloud, "Pick a box. Its contents will help you on your way."

Hayder never went to bed that night or on other nights when he played the video game. His eyes were bloodshot and he was reluctant to leave the television and lose his score. On other days, when Hayder played the video game all night, he arrived late at school because he drove his younger brothers to the middle school. Some of Hayder's teachers thought he was 'out of it' and on drugs, and unfortunately, his sleepless state was convincing evidence, as it had been on prior occasions when he stayed up to play video games.

Hayder also read avidly at work. At his second job in a fast food restaurant, he learned to use the cash register, and he asked the manager for a training manual or book about the register that he could take home to read and study. He was told that such a book did not exist. At a previous job, Hayder was allowed to take a book home and it helped him learn how to use the register. Hayder perceived reading to be relevant to doing his job well, and he lamented the lack of written instruction. Unlike the women in the study by Hull (2001), who were given reading and writing tests that were not all related to feeding forms into a machine, Hayder found that being able to read and respond to the menus, the cash register, pay checks, notices on the bulletin board at work was key to his survival in the work place. He also knew that for him, the sole bread winner in his family, literacy was vital to his family's well being. Unfortunately, after being fired from two jobs for being late 'just one time,' he had difficulty finding a new job elsewhere, and following the attacks of 11 September 2001, he suspected that his employers had tried to find a reason to fire him since other fast food workers had arrived late on occasion.

It was clear that Hayder's literacy practices were enacted differently. Success was mediated by the support available, i.e., a teacher who provided guidance and instruction, and tasks that allowed for an obvious and necessary connection being literacy and a job well done. At home, Hayder's parents could not read or write in their native language, but they placed a high value on Hayder's learning to read and write in English. Hayder always said that his parents wanted him to stay in school, yet there seemed to be a lack of emphasis or importance placed on attending school on a reg- 
ular basis - both for Hayder and his brothers. They needed him to be in an adult-like role, to support them and their family. The closest approximation of school-like literacy practices occurred in the work place, where Hayder actively sought to 'study' the manuals if they were available.

School was important to Hayder as long as it could provide the means to obtain a job. Ms. Sajac and Ms. Kleibel's classes provided opportunities to make such connections. With Ms. Sajac, he chatted occasionally about his life outside of school, and in Ms. Kleibel, Hayder found a teacher who understood the needs of a refugee. For example, when she discovered his interest in cars and repairing them, she provided him with books about cars during guided reading. She was also someone who inquired into his life and his problems. This was unusual in this young man's life, and given his absences and tardiness, it kept him connected to school life, but not for long. The scorpion bite became the metaphorical reality of failure both in and out of school, and reading for mayonnaise represents real life's marginalization from school literacy.

\section{The power of intertextuality in a refugee's life}

Ideally students should make across-text and across-content connections. When students read, they are often so focused with the content of a particular book, magazine, or newspaper article that they do not take the time to make across-text connections. Teachers know that students have to be taught to read beyond a single text. Hartman (1995) defines intertextuality as, 'a cognitive construction, where readers absorb, transpose, and build a mosaic of intersecting texts' (p. 521). There can be two types of intertextual links: linking ideas, people and events, and making social, cultural, political, and historical connections. Both forms of intertextual links have a place in the secondary classroom, and good readers connect the material they are currently reading with past reading experiences. In the case of ELL students, the enactment of intertextuality as a literacy event can help them inform their teachers of their prior experiences with formal schooling and literacy, and, thus, create some common understanding for the relevance of reading and writing instruction. Albright (2004) notes that students' reluctance to move beyond the localized meaning of an assignment makes it difficult for teachers to embrace reflective literacy activities. Students are so used to the formal structure of skills-based instruction that they feel unsafe and unsure of alternative approaches of higher levels of literacy competence. While following Hayder for two years, I found that students wanted to be heard; they wanted the past and present to be connected and to have meaning, and they wanted to do this in English.

Teachers often invite discussion of popular culture into the classroom because it serves as a referential point to help students make sense of what they are learning (Duff, 2002; Sullivan, 2002). When students are able to link something from their popular culture to what is being discussed in the classroom, they can make sense of the curriculum and connect it to the reality of their lives. Individuals construct mean- 
ing in various ways, and the elements of culture, history, and the nature of our language dramatically shapes how persons interpret and comprehend and relate to various texts. Morrell (2002) argues that teachers typically support popular culture in the classroom, but decide not to implement it because they believe it to be too cumbersome and threatening. They fear students will know more than they do, and they will lose authority. The opposite should be the case in secondary literacy classes. Students should engage with texts and popular culture they know so that they can teach teachers. Hayder welcomed explicit intellectual and social connections between his academic learning and popular culture because both offer tools of survival. As Moje (2002) points out, for many students literacy is a way of establishing identity, and I would argue that for many who seek refuge in the US, literacy is a tool for survival and that educators should know more about the innovative ways in which students and their families survive and integrate these into their instruction to create a more relevant curriculum. Maybe then, young men and women like Hayder would have an opportunity to use their education as cultural capital to transcend the harsh realities of poverty, isolation, shifting national and personal identities, linguistic competence, health problems, etc. Perhaps we ask too much of public schools, but in these unstable political times, they do offer stability and hope.

\section{Acknowledgements}

I thank the anonymous reviewers for pointing out areas of the paper that needed further clarification and explication. Bob Jeffrey at Ethnography and Education provided insightful suggestions and comments for revision that made the publication of the paper possible, and I am grateful for his thoughtful contribution.

\section{References}

Albright, J. (2004) The logic of our failures in literacy practices and teaching, Journal of Adolescent \& Adult Literacy, 44(7), 85-97.

Cunningham, P. \& Allington, R. (1999) Classrooms that work: they can all read and write (2nd edition) (New York, Longman).

Duff, P. A. (2002) Pop culture and ESL students: intertextuality, identity, and participation in classroom discussions, Journal of Adolescent \& Adult Literacy, 45(6), 482-487.

Emerson, R. M., Fretz, R. I. \& Shaw, L. L. (1995) Writing ethnographic fieldnotes (Chicago, IL, University of Chicago Press).

Erickson, F. \& Shultz, J. (1992) Students' experiences of the curriculum, in: P. W. Jackson (Ed.) Handbook of research on curriculum (New York, Macmillan), 72-95.

Guest, J. S. (1987) The Yezidis (New York, KPI).

Hartman, D. K. (1995) Eight readers reading: the intertextual links of proficient readers reading multiple passages, Reading Research Quarterly, 30(3), 520-561.

Hawkins, M. R. (2004) Researching English language and literacy development in schools, Educational Researcher, 33(3), 14-25. 
Hull, G. (2001) Hearing other voices: a critical assessment of popular views on literacy and work, in: S. W. Beck \& L. Nabors Oláh (Eds) Perspectives on language and literacy: beyond the here and now (Cambridge: Harvard Educational Review), 353-380.

Hull, G. \& Schultz, K. (2002) School's out! Bridging out-of-school literacies with classroom practice (New York, Teachers College Press).

Moje, E. (2002) But where are the youth? On the value of integrating youth culture into literacy theory, Educational Theory, 52(1), 97-120.

Moje, E., Dillon, D. \& O'Brien, D. (2000) Reexamining roles of learner, text, and context in secondary literacy, Journal of Educational Research, 93(3), 165-180.

Morrell, E. (2002) Toward a critical pedagogy of popular culture: literacy development among urban youth, Journal of Adolescent and Adult Literacy, 46(1), 72-78.

Pipher, M. (2002) The middle of everywhere: the world's refugees come to our town (New York, Harcourt, Inc.).

Spradley, J. P. (1979) The ethnographic interview (New York, Harcourt Brace Jovanovich College Publishers).

Sarroub, L. K. (2001) The sojourner experience of Yemeni American high school students: an ethnographic portrait, Harvard Educational Review, 7 1(3), 390-415.

Sarroub, L. K. (2002a) 'In-betweenness': religion and conflicting visions of literacy, Reading Research Quarterly, 37(2), 130-148.

Sarroub, L. K. (2002b) From neologisms to social practice: an analysis of the wanding of America, Anthropology and Education Quarterly, (33)3, 297-307.

Sarroub, L. K. (2004) Reframing for decisions: transforming talk about literacy assessment among teachers and researchers, in: R. Rogers (Ed.) New directions in critical discourse analysis: the role of language and learning in social transformation (Mahwah, NJ, Erlbaum), 97-1 16.

Sarroub, L. K. (2005) All American Yemeni girls: being Muslim in a public school (Philadelphia, PA, University of Pennsylvania Press).

Sullivan, P. (2002) Reception moments, modern literacy theory, and the teaching of literature, Journal of Adolescent and Adult Literacy, 45(7), 568-577. 